\title{
Quality of Life and Senior Travel Motivations and Expectations
}

\section{Rok Ovsenik}

Alma Mater Europaea-ECM

Email: rok.ovsenik@gmail.com

\section{Doi:10.5901/mjss.2015.v6n4s2p590}

\begin{abstract}
The purpose of this study was to investigate how the perceptions of the quality of life of the older people from various parts of Slovenia shape their requirements regarding the tourism travel. This research seeks to investigate the factors that impact the mobility of older people from the perspective of tourism travel. The current research model comprises three hypotheses to explore questions whether perceptions of the quality of life, active learning, and social networking stimulates the mobility of older people through the engagement in tourism travel. Study empirically validated the impact of quality of life dimensions of older people on the tourism travel activities. Perceptions of quality of life, active learning and social networking positively predict the travel mobility of older people.
\end{abstract}

Keywords: quality of life, tourism travel, social networking, learning, experience, active aging,

\section{Introduction}

A long and happy life was always a dream of human beings. The harmony of human actions, the quality of its work and quality spending of its leisure time are major components of quality of life of elderly people (Ovsenik.,M.,2013). How people think, how we learn and how it affects our behavior, how we fit into society, how we upgrade and transmit knowledge is unique to each individual (Ovsenik.,R.,Ovsenik.,M.,2015). The progress in many scientific disciplines like medicine, hygiene, sport and leisure, and nutrition makes this dream became true even for the non - privileged members of the modern society. Namely, the proportion of older people and especially the population of older people continually increases. This progress will inevitable provoke the changes that will take place in the demographic sphere and will affect all aspects of human life in the future. These changes will imply different family structure, new forms of social networks of older people and different living conditions for the human population. As a result, economy will operate in different circumstances regarding employment, technology and productivity. Societies will have to shape age models on which well-being of older people will depend (Bond et al, 2006). Further, societies will have to invent solutions that will allocate more time for care for others with a new quality of relations between generations. With the aging of human population all over the world, the quality of life of older people will rise the question of their active and mobile life. Further, the need for social and emotional support will dramatically increase. These changes will directly or indirectly affect people's habits, daily routines, social lives, beliefs and values, which may lead to the lower quality of life.

One of the essential elements of the quality of life is their ability and desire to be mobile. Active aging is the framework that bases on the motivation of older people to be mobile and to conduct a healthy and active life. It fundamentally links to the health status, diminishes the impact of loneliness and depression and helps to maintain and renew the social network of older people. Tourism traveling is one of the means of mobility of older people that contributes to the overall mobility and the quality of life of older people.

The framework of the present study illustrates how the perceptions of quality of life of older people influence their desire to engage in tourism traveling. In this study we will investigate, which dimensions of the perceived quality of life of senior tourists shape their expectations about the tourism travel. In this study we will aim at expectations of senior tourists to gain new experience of their behaviour. We will investigate their desire to live through the real life expectations, and through their desire for autonomy to plan and to choose the tourist travel that meets their lifestyle. Further, we will investigate what empowers senior tourist's self-esteem, what are his prerequisites to learn on tourism travel and how he experiences his corporeal mobility through the social networking with other people when traveling. 


\section{Theoretical Issues}

We have seen an increase in focus on subjective well-being and meaning of life of older people in recent years. The result of this activity is a proliferation of definitions and all kinds of measures and models of quality of life. As a result of this endeavor, there is no single definition or single measurement of the construct of quality of life. For Sennett (2003), Bond et al (2006), and Evans (2009), conceptualization and operationalization of the quality of life is an arduous process. Quality of life increasingly associates with qualitative, subjective measures and its objective quantitative aspects. The primary debates on quality of life focuses on the relative importance of subjective versus objective approaches. Researchers are interested in uni or multidimensional quality of life, in the role of values, in the place of self-evaluation, and in the cultural context (Xavier et al, 2003). Quality of life in old age is related to mobility, although the relationship is not clear, in part because the concept of movement lacks a precise definition (Metz, 2000).

\section{Quality of Life of Older People}

Quality of life refers to an overall assessment of one's life. It includes person's aspirations and achievements and closely connects to the overall satisfaction with life. Several aspects like social, physical, mental and financial determine it and usually interact with each other. Different factors like feelings of loneliness, self-care capacity, overall health, anxiety, and poor financial resources affect life quality of older people. They indicate the satisfaction with life of elderly people (Borg et al, 2006). According to Bowling (1999: 9) the quality of life is an individual response to the physical, mental and social effects of illness on daily living, which influences the personal satisfaction with life.

Quality of life and well-being are vague concepts. Corbin and Strauss (1987) argue that older people often relate their ability to preserve a sense of self with quality of life and with satisfaction with life. The literature dominates by discussion of the different definitions of quality of life of older people. There is evidence of concept's many applications in both scholarly discussion and public debate.

As human beings we hold perception of ideal self-concept, which we always present as the perception of subjectively real self-concept. Czaja (1975) compared six age groups regarding discrepancy between real and ideal selfconcepts and the relationship between life satisfaction and difference in self-concepts. He found significant differences among age groups for real and ideal concepts and life satisfaction. He also found differences between age groups regarding life satisfaction. Age of the respondents significantly correlated with real and ideal concepts and life satisfaction. Younger subjects had lower real and ideal self - ratings and were less satisfied with their lives than the elderly subjects. Naing et al (2010) study findings show that factors like education level, illness, self-esteem, family income, family relationship and family support significantly predict the quality of life of older people.

Backman and Hentinen (2001) related self-esteem and life satisfaction with functional capacity and activities of daily living of home-dwelling older people. The persons who responsibly cared for their selves, formally guided and independently carried out their daily activities without assistance from others. Those who showed abandoned self-care did not manage their daily activities without help. Life satisfaction was the highest among the formally guided persons and self-esteem among the responsible ones. Poor life satisfaction and self-esteem correlated with abandoned self-care behavior. It is evident that self-esteem is the fundamental factor of their perception of the quality of their life. It is an image the people have about themselves. Further, it is the indicator how they feel, how they react to work and leisure and what kind of relationship they have with their family, friends and other important people in their lives. In general, it is the complex attitude created in the socialization process in the community as a whole. Additionally, it is the basis of the view of older people of themselves and the world.

\section{Emotional Well-Being of Older People}

Another important dimension of the quality of life is the self-esteem. According to Železnik (2007) self-esteem is an individual feeling of self-worth and self-respect. It is a dynamic category and may change in the life course of a person. Besides, it may follow new and different path with the changes of the lifestyle and social roles. Such changes often occur when older people become more and more dependent of others. And dependency provokes the feelings of uselessness. Hunter et al (1981) confirmed these statements studying a sample of older people to see what background and personality characteristics form their low or high self-esteem. The low-esteem group had poorer self-reported health, more pain and greater disability. Further, the low-esteem group had significantly higher scores on depression, anxiety and somatization. Other researchers like Ayranci and Ozdag (2006) found out that elderly people who live independently can preserve self-esteem by maintaining their health. Further, Bradley (2002) studied the effects of relocation of old 
people to a retirement facility and its effect on person's self-concept. His research suggests that residing at a retirement facility is a source of stigma for older people. It is so because of the way it affects their relationship with others.

Cotter (2009) study shows that the aging process leads to normative age-related bodily and functional declines and numerous social changes and life events that potentially threaten the self-concept. The difficult changes that older people may face such as death of spouse or severe medical problems can lead to depression or development of low self-esteem and overall dissatisfaction with life. Coleman et al (1993) report in follow-up study show that help with household tasks, a negative attitude of ageing, and perceived inactivity are symptoms of low self-esteem. Contrary, high self-esteem associates with resilience against depression. Resilience is the ability to cope with life's frustrations without falling apart. Proper treatment doesn't suppress emotions or dull a person's ability to feel things deeply. It builds a protective layer and emotional resilience to safeguard a depressive from becoming overwhelmed and disabled by the difficulties of daily life. Studies show that critical factors of quality of life such as independence-related factors, environmental factors, and adaptive factors relate actively. Being active and satisfied with life is an adequate protection against building of low selfesteem and depression. On the other hand the active and mobile life fosters positive future expectations and leads to the motivation to explore yet unused personal potentials.

\section{Active Learning of Older People}

Active learning is an imperative process for all generations. It is a way how to cope with everyday problems and situations in all life stages. Suc learning pattern is significant for a generations of older people that must have equal opportunity to learn (Naumanen and Tukiainen, 2008; Smith, 1983). Findings of empirical research from Naumanen and Tukiainen (2008) show that that the continuing education programs for the older people need peer-support through club-based activities. Japelj et al (2006) report shows that Slovenia met the challenges for the education of older people and founded The University of the Third Age through the Gerontological Association. The institution offers a diversity of study programs, organized research journeys and other possibilities for learning.

Niederfranke (1992) argues that education for the older people contributes to connecting experiences and the capacity of elderly people to cope with their situation with up-to-date knowledge and with new strategies for solving problems. On the level of individual level educational situation encourages and promotes a transfer of knowledge between older people and younger people. Further, study shows that learning is an important inhibitor of cognitive decline among older adults (Kirkwood et al, 2008). Schuller et al (2004) study aims at another important role of learning in the fight against depression.

Feinstein et al (2003) and Field (2009) link participation in learning with life satisfaction and well-being. Older learners report optimism and self-rated well-being. Schleiter (2008) recent study showed that elderly people identify learning as an important element in their subjective well-being.

Learning is a crucial factor in the process of building life satisfaction and realizing of the future expectations. These findings correspond with Schuller et al (2004) study that shows how important is the role of the continuous learning in the struggle against depressive feelings. Besides, they are similar with Feinstein et al (2003), Field (2009), and Schleiter (2008) studies link continuous learning with life satisfaction and well-being producing optimistic view of life.

\section{Social Networking of Older People}

Shu et al (2003) explored the self-concept of older people residing in retirement centres as well as its relationship to function of daily living and subjective well-being. The subjects comprised a convenience sample of people aged 65 or older from a retirement center in the south of Taiwan. The results show that the older people residing in the retirement center have significantly lower Personal Self and Family Self scores. Further, results indicate that more aged people scoring low have small interaction with others and they do not participate in various social networks. As a result, they report negative self-concept. Results correspond with the findings of the study by Nillson et al (2006) who found out that social capital both at individual and community level directly associates with quality of life of older people in rural environment. Železnik (2007) found out that self-esteem is an indicator of more aged people feelings and their reactions to work and leisure and the symbol of the relationship they have with their family. Establishing formal and informal social networks promotes the life satisfaction of the older people, and releases their social, intellectual and mental potentials.

Older people like to travel. Metz and Underwood (2005:5) relate this characteristics of older people with life expectancy. Darcy et al (2011: 179) argue that older travellers are increasingly healthy and affluent and travel more. They are also more demanding and are continually looking for opportunities for special interest travel and they seek innovative experiences. Gibson and Singleton (2012: 198) argue that older people increasingly place travel as a higher priority in 
their retirement years. Patterson (2006) research findings reveal that older travellers want variety, clear copy in travel brochures, reliable information and value for their money. Thus, older tourists seek new acquaintances to empower their desire for new adventures and experiences. Scott et al (2010: 170) reveal that older people have the desire to be young again and they want to engage in exiting and adventurous activities. The research has also shown that older people prefer real life experiences where they can learn and broaden their minds. Buhalis and Darcy (2011: 179) argue that more aged people are increasingly healthy and affluent and they are travelling more. Besides, they are more discerning and demanding and continually looking for new opportunities for unique travel.

Thus, the present study has three goals. First, we were interested and wanted to determine whether the perception of the quality of life of older people affected the desire for tourism travel. Second, we examined whether the different activities and desires to learning motivate older people to travel. Finally, we endeavored to test the relation between the social participation of older people and their desire to travel. Basing on previous goals we modelled three hypotheses:

- H1: Older people who perceive good quality of their life like to travel more.

- H2: Older people who learn actively like to travel as tourists.

- H3: Older people who want to meet new acquaintances and to gain new experiences like tourism traveling.

\section{Method}

To test the results of the impact of quality of life on the tourism travel of older people we decided to use quantitative methods. We conducted three statistical frameworks. The first one was descriptive statistics, the second was the exploratory factor analysis. Finally, we performed multiple regression analysis to test the hypotheses of the study. We used Statistica 7.0 statistical software to analyze the data from the study. Further, we used statistical software SPSS 20.0 to test the appropriateness of the factor analysis for the data reduction and for the extraction of the latent factors.

\section{Participants}

To test the impact of different dimensions of quality of life on the desire to tourism travel, we recruited 221 retired older people from various parts of Slovenia.

Table 1: Sample of respondents in a research study

\begin{tabular}{|cl|c|c|}
\hline Sample & $\mathrm{N}=221$ & \\
\hline Sex & Women & Men \\
Age range & 82 & 139 \\
& & Range & Average \\
Education & & $51-100$ years & 71,08 years \\
$\bullet \quad$ Preliminary school & Participant education & \\
- & High school & 86 & \\
$\bullet \quad$ College & 97 & \\
$\bullet \quad$ Post-graduate & 30 & \\
- Doctorate & 5 & \\
\hline
\end{tabular}

The recruitment sample included 82 men and 139 women. Ages of the participants ranged from 51 to 100 years and the average of the participants was 71,08 years. In respect to education, 86 has some preliminary school, 97 , were high school graduates, 30 college graduates, 5 were post-graduate, and 3 held doctorate from various disciplines. The most frequent professions of the participants in our study before retirement were: public servant, technician, professor, teacher, nurse, industry worker, housewife, supervisor in industry, and doctor of medicine.

\section{Instrument}

To develop a measurement scales of quality of life is a difficult task because there is not substantial standard for it. Feelings about life are subjective, and various factors of well-being are individual too. On the other hand, there is a large body of quantitative research methods that identified core factors of quality of life of elderly people, which can be productively used to measure the quality of life. We self-developed the survey instrument. The 26 -item questionnaire 
consisted of four to ten items for each of the six dimensions. Items reflected the specific content of the perception of the quality of life of older people: quality of life, emotional well-being, their active learning, social networking.

We interspersed items from the scales randomly throughout the instrument. Each item in the questionnaire has a five point interval scale ranging from 5 (favorable) to 1 (unfavorable). Questionnaire contained eight demographics items related to the respondent's level within the organization: education, profession, sex, age, dwelling conditions, financial security, health, and time in retirement. We measured these items on ordinal or categorical scale. To measure the travel behavior of the respondents, we used the frequency of their tourism travel in the previous year.

We pre-tested the questionnaire with three randomly chosen retired elderly people. One was a retiree with a PhD in political sciences, the other was a housewife, and the third was a technician. We revised the questionnaire on the basis of their recommendations. Because some respondents were apt to have minimal education, they recommended some changes in wording. We sent questionnaires by post or by e-mail to randomly chosen respondents who agreed to participate in the study. The students of a Medical College of University of Maribor in Slovenia approached to some respondents personally.

\section{Results of the Study}

We analyzed the data we obtained from the respondents in the study on three levels. Firstly, we used descriptive statistics to describe the data. Secondly, we used factor analysis to reduce the data and to obtain the latent factors of quality of life of older people. Finally, we conducted multiple regression analysis to test the hypotheses of the theoretical construct of the study.

\section{Factor Analysis}

We used Principal component factor analysis to obtain small number of latent factors and to prove the theoretical construct of the research. This type of analysis estimates factors which influence responses on observed variables and allow to describe and identify the number of latent constructs or elements. It helps to explore the underlying factor structure of a set of variables it measures.

Firstly, we assessed the appropriateness of using factor analysis on data with Kaiser-Meyer-Olkin measure. The diagonal element is greater than $0,5(\mathrm{KMO}=0,817)$ and indicates that factor analysis for the set of data is appropriate. Secondly, we conducted the Bartlett's test of Sphericity (Snedecor and Cochran, 1983) shows that variables are powerfully connected ( $D F=352, p=0,000$ ). We can conclude that factor analysis is the proper method for the data reduction and for the extraction of latent factors.

Table 2: KMO and Bartlett's Test

\begin{tabular}{|c|c|c|}
\hline Kaiser-Meyer-Olkin Measure of Sampling Adequacy. &, 817 \\
\hline \multirow{3}{*}{ Bartlett's Test of Sphericity } & Approx. Chi-Square & 2033,439 \\
\cline { 2 - 3 } & $\mathrm{df}$ & 351 \\
\cline { 2 - 3 } & Sig. &, 000 \\
\hline
\end{tabular}

We included 26 variables in the factor analysis (Table 1). Our intention was to extract four latent factors that represent the theoretical construct explaining the perceptions of older people on the quality of their life. The four latent factors explain the $47,845 \%$ of common variance of the factors. The first factor we named: »Quality life" explains $24,792 \%$ of variance and comprises ten variables describing the perception of the quality of life of older people. This factor explains the strong desire to fulfill more aged people expectations. It shows that they think that many things that they wanted to do in the past they will leave to the future. Further, older people think that many unfulfilled expectations are waiting its realization. They think that retirement is the game that they have to play actively and jointly create community and full life experience with other people. It is important to emphasize that in this factor older people recognize new challenges for the future. They have the desire to stay fit, plan their activities carefully and think that the future is there to use their mental, intellectual and social potentials.

The second factor: "Emotional well-being" explains 8,869 \% of variance in the factor model and comprises of z variables. These variables describe the emotional state of the respondents in our research.

It encompass many aspects of the causes for low- esteem of elderly people. Put it differently, the opposite factor of depression is resilience: the ability to cope with life's frustrations without falling apart. Respondents described various 
problems that accompany their process of retirement. One of the strongest is the sadness and resentment along with boring, feeling of emptiness and low opinion of oneself. Respondents report problems with adaptation to retirement life, leaving behind the devotion to meaningful work. Further, they report fear of changes, worries for the future and expected financial problems. This notion is similar to that of Cotter (2009) which shows that aging process leads to normative agerelated bodily and functional declines and numerous social changes and life events that potentially threaten the selfconcept.

Further, the third factor "Active learning" explains only 7,608 \% of variance and comprises of 5 variables that describe the learning pattern of the respondents. The third factor explains the desire to learn foreign languages, to document important life events, desire for corporeal and virtual travel through Internet and experience places, people and culture. This factor shows the findings, which are similar to those of Feinstein et al (2003) and Field (2009) that connect participation in learning with life satisfaction and well-being. When they learn, elderly people express optimism and selfrated well-being.

Finally, we named the fourth factor: "Social networking" explains $6,576 \%$ of variance and comprises of four variables that describe the building and maintaining of the social network of an older person. When older people think that they are capable of producing bonding and informal network social capital, they have a good starting point to engage in the social fabrics of local community. The opportunity to actively participate in voluntary activities in local community that correspond their abilities, gives them an opportunity to exploit their potentials. On the other hand they have the opportunity to meet new people and to experience new adventures. These findings correspond to that of McMichael and Manderson (2004) who argue that people are happier if they ultimately feel they belong to a community and have various connections.

Table 3: Results of principal factor analysis

\begin{tabular}{|c|c|c|c|c|c|c|}
\hline & 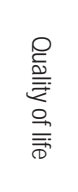 & 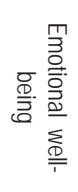 & 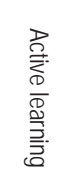 & 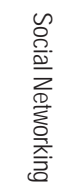 & $\begin{array}{l}3 \\
\stackrel{\mathbb{D}}{J} \\
\stackrel{2}{5}\end{array}$ & 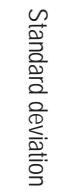 \\
\hline Now, when I am retired I take enough time and consume healthy food. & 0,609 & $-0,112$ & 0,191 & $-0,156$ & 3,314 & 1,147 \\
\hline It is of utmost importance that I do what I want. & 0,611 & 0,204 & 0,031 & 0,199 & 4,138 & 0,944 \\
\hline Contacts with my family members empower my self-concept. & 0,570 & 0,049 & $-0,296$ & 0,183 & 4,164 & 0,934 \\
\hline I am convinced that I deserve all good in the world. & 0,677 & 0,035 & $-0,003$ & 0,235 & 4,077 & 0,797 \\
\hline I am in a good mood. & 0,578 & 0,353 & 0,125 & 0,163 & 3,869 & 0,966 \\
\hline I am proud of my life achievements. & 0,633 & 0,188 & 0,164 & 0,050 & 4,155 & 0,876 \\
\hline I enjoy the achievements that I reached since I have been retired. & 0,660 & 0,024 & 0,151 & 0,241 & 3,739 & 1,009 \\
\hline I plan my activities since I have been retired. & 0,564 & $-0,012$ & 0,179 & 0,096 & 3,223 & 1,206 \\
\hline I have a feeling the time has come for the fulfilment of my expectations. & 0,457 & 0,015 & 0,372 & 0,246 & 3,073 & 1,110 \\
\hline I am the actor in the game called retirement. & 0,462 & $-0,025$ & 0,170 & 0,326 & 3,220 & 1,119 \\
\hline I feel sad and depressed when I realize that I am retired. & $-0,328$ & $-0,633$ & $-0,005$ & $-0,119$ & 1,837 & 1,066 \\
\hline The initial feeling of pleasure to be retired changed to the feelings of emptiness and boredom. & $-0,228$ & $-0,676$ & $-0,089$ & 0,004 & 2,114 & 1,152 \\
\hline I am worried sometimes about the future. & 0,017 & $-0,569$ & 0,002 & $-0,205$ & 3,273 & 1,205 \\
\hline It is hard for me to accept the fact that I can afford less since I have been retired. & $-0,030$ & $-0,540$ & $-0,030$ & 0,000 & 2,719 & 1,257 \\
\hline I think that my retirement allows me to go on with my life without any significant changes. & 0,345 & 0,505 & 0,066 & 0,112 & 3,846 & 1,015 \\
\hline My life would be more complete if I would have more friends. & 0,019 & $-0,583$ & $-0,161$ & 0,082 & 2,638 & 1,174 \\
\hline When I look at my old photos I feel that I am the part of the story they represent. & 0,193 & $-0,520$ & $-0,004$ & $-0,028$ & 3,400 & 1,234 \\
\hline I use Internet a lot since I have been retired. & 0,133 & 0,235 & 0,694 & $-0,055$ & 2,005 & 1,370 \\
\hline I take photographs to preserve memories and important moments in my life. & 0,139 & 0,009 & 0,645 & 0,090 & 2,239 & 1,341 \\
\hline I learn foreign languages. & 0,083 & 0,146 & 0,725 & 0,192 & 1,605 & 1,060 \\
\hline I attend the lectures in the programs of the University for the third period of life. & 0,015 & $-0,129$ & 0,671 & 0,269 & 1,562 & 0,971 \\
\hline I am satisfied with my sexual life. & 0,341 & 0,297 & 0,487 & $-0,050$ & 2,693 & 1,350 \\
\hline New acquaintances bring me the desire for new adventures and experiences. & 0,358 & 0,100 & 0,221 & 0,559 & 3,018 & 1,187 \\
\hline I actively participate in the community life. & 0,203 & 0,079 & 0,028 & 0,859 & 2,514 & 1,343 \\
\hline I have an opportunity to participate in the activities of local community that match my abilities. & 0,287 & 0,204 & 0,165 & 0,717 & 2,918 & 1,353 \\
\hline I participate as a volunteer in a local community. & 0,095 & $-0,015$ & 0,112 & 0,811 & 1,912 & 1,313 \\
\hline
\end{tabular}

To test the internal consistency, that is the closeness of the relation of a set of items as a group or factor, we used Cronbach's alpha coefficient of reliability or consistency. Results show that Quality of life (Cronbach's Alpha $=.825$ ), 
active learning (Cronbach's Alpha $=.732$ ) and social networking (Cronbach's Alpha $=.821$ ), have high internal consistency. Emotional well-being (Cronbach's Alpha = .495) does not exceed the threshold of 0.7 (Nunally, 1994), so we dropped it from the further analysis.

\section{Regression Analysis}

The objective of our research was to examine how the perception of older people about their quality of life motivates their mobility in the form of tourism travel. We regressed the dimensions of quality of life of older people on frequency of tourism traveling. The quality model consists of three independent variables: Quality of life, Active Learning, and Social networking and the dependent variable Tourism traveling. Factor Emotional well-being failed to meet the reliability criteria (Cronbach's Alpha $=0,459)$, the accepted level of the composite reliability so we decide to drop it from the further analysis. The output of the multiple regression model shows the results of fitting a multiple linear regression model to describe the relationship between tourism travel and three independent variables. The equation of the fitted model is:

Tourism travel $=-1,1753+0,264718^{*}$ quality of life $+0,246797^{*}$ active learning $+0,130007^{*}$ social networking

Since the $p$-value in Table 2 is less than 0,05 , there is a statistically significant relationship between the variables at the $95,0 \%$ confidence level. The coefficient of determination $\left(R^{2}\right)$ we can define as the proportion of variance in the data explained by the statistical model and not by random error terms or non-included constructs. In addition, we provide information on the adjusted $\mathrm{R}^{2}$, which accounts for the number of independent variables (Theil, 1961). In the research model the $\mathrm{R}^{2}$ statistic indicates that the model as fitted explains $21,182 \%$ of the variability in tourism travel. The adjusted $\mathrm{R}^{2}$ statistic, which is more suitable for comparing models with different numbers of independent variables, is $20,092 \%$. The standard error of the estimate shows the standard deviation of the residuals to be 0,778 . The average value of the residuals (MAE) in the model is 0,605 . We used the Durbin -Watson (DW) statistic test of the residuals to determine if there is any significant correlation between independent variables. Since the $p$-value is greater than 0,05 , there is no indication of serial autocorrelation in the residuals at the $95,0 \%$ confidence level.

Table 4: results of multiple regression analysis

\begin{tabular}{lc}
\hline $\mathrm{R}^{2}$ (adjusted for d. f.) & 21,181 percent \\
Standard Error of Est. & 0,778 \\
Mean absolute error & 0,605 \\
Durbin-Watson statistic & $1,9837(\mathrm{p}=0,452)$ \\
F-ratio & 19,44 \\
p-value & 0,0000 \\
\hline
\end{tabular}

According to the results of regression analysis we can confirm and accept the first hypothesis ( $\mathrm{H} 1)$ : "Older people who perceive sound quality of their life like to travel more." The independent variable Quality of life has the highest correlation in the model (Beta $=0,264 ; p=0,0003$ ). Consequently, it is in statistically significant and positive relation to the tourism traveling. We can conclude that quality of life positively connects to the mobility, which gives older people sense of autonomy and independence.

Further, independent variable: »Active learning" has a little lower correlation in the model (Beta $=0,247 ; p=0$, 0004). Since the relationship between this variable and independent variable Tourism traveling is statistically significant and positive, we can confirm the second hypothesis in the model $(\mathrm{H} 2)$ :" Older people who learn actively like to travel as tourists." Obviously, when older people learn actively they have the desire for gaining of new experiences, which the tourism travel can deliver.

"Social networking" has the lowest correlation in the model (Beta $=0,130 ; p=0,0289$ ). We can conclude that the relationship between this variable and dependent variable Tourism traveling is statistically significant and positive. Again, we can confirm the third hypothesis: (H3): "Older people who want to meet new acquaintances and to gain new experiences like tourism traveling."

\section{Discussion}

The research model we propose provides a framework for understanding motives of older people to maintain their mobility in the form of a tourism travel. Perceptions of older people about the quality of life significantly explain the desire for tourism travel. Older person perception of his or her quality of life significantly associates with the frequency of travel 
traveling. He feels that the tourism travel is a new quality in his life and a new achievement on the field of mobility. Older tourist has a strong urge to show to his family, relatives and friends his or her results from tourism travel. He has to be proud of his life achievements, so he has to enjoy and engage in a new adventures that tourism travel brings. Older tourist's results define his self-concept, boost his self-esteem and establish his status in the society. Feeling of autonomy in planning of activities of a tourism travel and the feeling that he is the actor in his own game empowers his desire to travel. He has to be aware of what he can do and what he wants and he will enjoy traveling, consuming healthy food and he want to be in a good mood.

The results of positive and significant relationship between active learning and frequency of traveling suggest that the positive attitude to the active learning motivates the older person to become mobile and to gain new experiences. Older tourists seek novelties and they are continually looking for new adventures. The results also show that more elderly tourists like variety in learning, so they will find various modes of learning and gaining new experiences when on tourism travel. They want their experiences with tourism traveling to be memorable and he wants to have an opportunity to publish his memories on social media. Older tourists prefer life experiences, to learn from them and to broaden their views. Results corroborate the desire and the intention of more aged people to gain new knowledge and new experiences by engaging in the tourism travel activities. Engagement in different learning pursuits seems to be the vantage point that accelerates the mobility of and older person.

The results also show that social networking of an older person appears to be positively and associated with the frequency of tourism traveling. Social networking inevitably associates with the desire of older people for new adventures and experiences. Older people in our study actively participate in the community life. This statement implies that once an older person actively participates in the community life, his or her desire to be mobile strengthens. He likes to broaden his social network with the people he wants. Further, he wants to participate in every community endeavour that matches his abilities. Such a person wishes to engage in tourism traveling, which can match his skills to perform and to gain new experiences. He also wants to associate with the people when traveling that can become his new acquaintances and the part of his social network. For him it is important the feeling that contacts with other people when traveling can empower his self-concept, especially when he shares the joy of going with them. One of the major findings of this study is that the tourism traveling is what he wants without any unnecessary constraints, which the organizers of tourism travel impose. It is evident that older tourists engage in volitional behaviour because it is self-relevant, has subjective meaning and is important to them.

We can conclude from the results of the study that social networking builds the foundation for the positive stimuli of an older people to travel and to strengthen his social network. Older person is mobile because such behaviour is selfrelevant. It seems that such behaviour has subjective meaning and contributes to the quality of life of an older person. Therefore, a possible explanation of the results of the study is that an older person consider tourism traveling as a mean to achieve higher quality of life. Enhancing the positive perceptions of the quality of life of an older person through the various means of mobility becomes a necessity.

\section{Conclusions and Implications}

Life expectancy of an older population in the world increases. Older people are growing in the dominant social group in the world. They are increasingly healthy and affluent. It is important to note that older people have often tourism travel on their agenda. They are demanding as tourists and are continually looking for opportunities for special interest travel. According to their beliefs, they usually seek innovative experiences and they want variety when traveling. Further, they travel in tourism to ask new acquaintances to empower their desire for new adventures and experiences. They want to be young again and they want to engage in exiting and adventurous activities from real life and broaden their minds.

Many several stakeholders like tourism managers, travel agencies, and organizers of tourism activities, gerontologists and workers in communities of practice can use the findings of this study. They can use these results to improve the quality of life of older people, to plan active aging, and to introduce the integral tourism products to potential older travellers. Results of the study reveal additional dimension of the quality of life of older people and gives the insight into the possibilities to enhance the mobility of older people.

This study has some limitations too. We focus on perceptions of quality of life of older people to explain the social behaviour using quantitative approach. This approach gives the general notion of tourism mobility of older people, but fails the in-depth insight. Future studies should aim at revealing the deep ingrained expectations of older people to recognize the factors that can enhance their mobility. We suggest a qualitative study with in-depth interviews in various groups with different predispositions for mobility.

This study has some limitations. The respondents in the study belong to the right group of older people that are 
retired and engage in tourism travel. We know from the previous research that older men and women differ in their definition of the quality of life. The number of men and women participants in the study differs significantly. The sample of the respondents is to low and we cannot generalize the results of the study. Further, we do not know the attitudes of the people who did not want to participate in the study. Further research will be useful to investigate the attitudes of underrepresented older people about the tourism travel.

\section{References}

Ayranci, U. \& N. Ozdag, N. (2005). Health of Elderly: Importance of Nursing and Family Medicine Care. The Internet Journal of Geriatrics and Gerontology. vol. 3, no. 1.

Backman, K. R. N., Hentinen, M. R. N. (2001). Factors associated with the self-care of home-dwelling elderly. Vol. 15, no. 3, pp. 195202.

Bond, J., Corner, L. (2006). The future of well-being: quality of life of older people in the twenty-first century, in J. Vincent, C. Phillipson and M. Downs (Eds), The Futures of Old Age. London, Sage, pp. 154-160.

Borg, C., Halberg I. R, Blomquist, K. (2006). Life satisfaction among older people (65+) with reduced self-care capacity: the relationship to social, health and financial aspects. Journal of Clinical Nursing, vol. 15, no. 5, pp. 607-18.

Bowling, A., Fleissig, A., Gabriel, Z., Banister, D., Dykes; J., Dowding, L., Sutton, S. and Evans, O. (2003). Let's ask them: a national survey of definitions of quality of life and its enhancement among people aged 65 and over. International Journal of Ageing and Human Development, vol. 56, no. 4: 269-306.

Bradley, J. F. (2002). The stigma of relocation to a retirement facility. Journal of Aging Studies. Vol. 4, no. 1, pp. 47-59.

Buhalis, D., Darcy, S. (Eds.) (2011). Accessible tourism: Concepts and Issues. New York, Channel View Publication.

Coleman, P., Aubin, A., Robinson, M., Ivani-Chalian, C., Briggs, R. (1993). Predictors of depressive symptoms and low self-esteem in a follow-up study of elderly people over 10 years. International Journal of Geriatric Psychiatry, vol. 8, no. 4, pp. 343-349.

Cotter, V. T., (2009). Self-concept in Older Adults: An Integrative Review of Empirical Literature. Holistic Nursing Practice: vol. 23, no. 6 , pp. 335-348.

Czaja, S. J. (1975). Age differences in life satisfaction as a function of discrepancy between real and ideal self - concepts Experimental Aging Research: An International Journal Devoted to the Scientific Study of the Aging Process. vol. 1, no.1, pp. 81-89.

Feinstein, L., Hammond, C. Woods, L., Preston, J., Bynner, J. (2003). The Contribution of Adult learning to Health and Social Capital, Research Report 8, London: Centre for Research on the Wider Benefits of Learning.

Field, J. (2009). Lifelong learning, welfare and mental well-being into older age: trends and policies in Europe. Hong Kong Institute of Education.

Gibson, H., Singleton, J. F. (Eds) (2012). Leisure and Aging: Theory and practice. Leeds. Human Kinetics.

Hunter, K. I., Linn, M. W., Harris, R. (1981). Characteristics of High and Low Self-Esteem in the Elderly. The International Journal of Aging and Human Development. vol. 14, no. 2, pp. 117-126.

Japelj, M. Š., Kokol, P., Mičetić-Turk, D., Blažun, H. (2006). Overview on health promotion for older people in Slovenia. PRO health elderly, pp. 1-20.

Kirkwood, T., Bond, J., May, C., Mckeith, I., The, M.M. (2008). Mental Capital through Life: Future Challenges, the Government Office of Science, London.

McAuley, Katula, J., Duncan, E. T. Mihalko, S. L (2000). Physical activity, self-esteem, and self-efficacy relationships in older adults: a randomized control trial. Annual Behavior Medical, 22 (2): 131-139.

McMichael, C., Manderson, L. (2004). Somali women an well-being: Social networks and social capital among immigrant women in Australia, Human Organization, vol. 63, no. 1, pp. 88-99.

Metz, D. \& Underwood, M. (2005). Older, richer, fitter: identifying the consumer needs of Britain's ageing population. Age Concern England. London.

Naing, M. M., Nanthamongkolchai, S., Munsawaeegsub, C. (2010). Quality of Life of the Elderly People in Einme Township Irrawaddy Division, Myanmar, Asian Journal of Public health, vol. 1, no. 2, pp. 4-10.

Naumanen, M., Tukiainen, M. (2008). Practices in old age ICT- Education. IADID Conference on Cognition and Exploratory Learning in Digital Age, (CELDA).

Niederfranke, A. (1992). Education for the elderly: New directions in a changing Europe. International review of education. 1992, vol. 38, no. 4, pp. 327-341.

Nilsson, J., Rana, A. K., Kabir, Z. N. (2006). Social capital and quality of life in old age: results from a cross-sectional study in rural Bangladesh. Journal of Aging and Health, vol. 18, no. 3, pp. $419-434$.

Nunnally, J. C., \& Bernstein, I. H. (1994). Psychometric Theory (3rd Ed.). New York: McGraw-Hill.

Ovsenik, M. (2013). Intelectual capital as a challange for intergenerational gap (2013).Kranj: Modern Organization: Faculty of Organizational Sciences.

Ovsenik, R., Ovsenik, M., (2015). Quo Vadis Ageing. Maribor: AMEU-ECM.

Patterson, R. (2006). Growing older: Tourism and Leisure Behaviour of Older Adults: Tourism and leisure behaviour of older adults. CAB International, Cambridge, Massachusetts.

Schleiter, A. (2008). Glück, Freude, Wohlbefinden-welche Rolle spielt das Lernen? Ergebnisse einer repräsentativen Umfrage unter 
Erwachsenen in Deutschland, Gütersloh: Bertelsmann Stiftung.

Scott, N., Laws, E., Boksberger, P. (Eds) (2010). Marketing of Tourism Experiences. New York, Routledge.

Shu, B. C., Huang, C., Chen, B. C. (2003). Factors related to self-concept of elderly residing in a retirement center. Journal of Nursing. vol. 11, no. 1, pp. 1-8.

Schuller, T., Preston, J., Hammond, C., Bassett-Grundy, A., Bynner, J. (2004). The benefits of learning: the impacts of formal and informal education on social capital, health and family life, London: Routledge.

Smith, T. L. (1983). Denmark: The elderly living in style. British medical journal, vol. 27, no.8, pp. 1053-1055.

Snedecor, G. W., Cochran, W. G. (1989). Statistical Methods, Eighth Edition, lowa State University Press.

Theil, H. (1961). Economic Forecasts and Policy. North-Holland, Amsterdam.

Železnik, D. (2007). Self-care of the home-dwelling elderly people living in Slovenia. Acta Universitatis Ouluensis, D Medica 954. 